\title{
Handling Qualities in Rotorcraft Conceptual Design
}

\author{
Andrea Zanoni $^{1}\left(\mathbb{D} \cdot\right.$ Giacomo Gerosa $^{1} \cdot$ Luigi Di Lallo $^{1} \cdot$ Pierangelo Masarati ${ }^{1} \mathbb{C}$
}

Received: 30 September 2021 / Revised: 15 January 2022 / Accepted: 19 January 2022 / Published online: 3 February 2022

(c) The Author(s) 2022

\begin{abstract}
This paper presents the development of a rotorcraft conceptual design tool able to incorporate handling qualities assessment at an early design stage. After a first conventional sizing, performed utilizing NASA's NDARC software, a linearized model of the rotorcraft flight mechanics is built. The linear model is augmented by a simplified control system, designed according to structured $H_{\infty}$ techniques, to determine augmentation requirements, rather than design the actual flight control system. ADS-33 Bandwidth and Phase-Delay standards are exploited to objectively assess the handling qualities of the current design and to drive an iterative redesign process aimed at enhancing the handling qualities ratings. The rotorcraft parameters resulting from the augmented sizing are subsequently used to automatically generate a real-time capable multibody model, which can be used for the subjective evaluation of its handling qualities via piloted flight simulation. The tool capabilities are demonstrated by designing a conventional lightweight helicopter of the class of the Airbus Helicopters BO105.
\end{abstract}

Keywords Rotorcraft conceptual design $\cdot$ Handling qualities $\cdot$ Robust control $\cdot$ Flight dynamics

\section{List of Symbols}

$(\cdot)_{/ j} \quad$ Partial derivative with respect to $j$

$\Omega \quad$ Main rotor angular velocity $\mathrm{rad} \mathrm{s}^{-1}$

$\omega_{\mathrm{BW} \phi} \quad$ Bandwidth $\left(\phi\right.$ for roll) $\mathrm{rad} \mathrm{s}^{-1}$

$\phi, \theta \quad$ Euler angles for roll and pitch rad

$\tau_{f} \quad$ Flapping time constant $\mathrm{s}$

$\tau_{p \phi} \quad$ Phase-Delay ( $\phi$ for roll) $\mathrm{s}$

$\theta_{0}, \theta_{0 T} \quad$ Main rotor and tail rotor collective pitch rad

$\theta_{1 s}, \theta_{1 c} \quad$ Longitudinal and lateral cyclic pitch rad

$g \quad$ Gravity acceleration $\mathrm{m} \mathrm{s}^{-2}$

$I_{x x}, I_{y y}, I_{z z} \quad$ Roll, pitch and yaw moments of inertia $\mathrm{kg} \mathrm{m}^{2}$

$I_{x z} \quad$ Roll-yaw product of inertia $\mathrm{kg} \mathrm{m}^{2}$

$L, M, N \quad$ Body axis roll, pitch and yaw moment components $\mathrm{N}$ m

$L_{f}, M_{f} \quad$ Longitudinal and lateral rotor flapping moment components $\mathrm{N}$ m

m Rotorcraft mass kg

Pierangelo Masarati

pierangelo.masarati@polimi.it

Andrea Zanoni

andrea.zanoni@polimi.it

Giacomo Gerosa

giacomo.gerosa@mail.polimi.it

Luigi Di Lallo

luigi.dilallo@mail.polimi.it

1 Politecnico di Milano, Milan, Italy

\begin{tabular}{|c|c|}
\hline$p, q, r$ & Roll, pitch and yaw angular rates rad s ${ }^{-1}$ \\
\hline$R$ & Main rotor radius $m$ \\
\hline$u, v, w$ & $\begin{array}{l}\text { Longitudinal, lateral and vertical velocity } \\
\text { components } \mathrm{m} \mathrm{s}^{-1}\end{array}$ \\
\hline$U_{e}, V_{e}, W_{e}$ & $\begin{array}{l}\text { Longitudinal, lateral and vertical trim velocity } \\
\text { components } \mathrm{m} \mathrm{s}^{-1}\end{array}$ \\
\hline$V_{\text {tip }}$ & Main rotor tip speed $\mathrm{m} \mathrm{s}^{-1}$ \\
\hline$X, Y, Z$ & $\begin{array}{l}\text { Body axis longitudinal, lateral and vertical } \\
\text { force components } \mathrm{N}\end{array}$ \\
\hline$\beta_{1 c}, \beta_{1 s}$ & Longitudinal and lateral flapping angles rad \\
\hline$\Phi_{e}, \Theta_{e}$ & Trim Euler angles for roll and pitch rad \\
\hline MTOW & Maximum take-off weight kg \\
\hline PENG & Engine power available kW \\
\hline
\end{tabular}

\section{Introduction}

The conceptual design of rotorcraft, often referred to as sizing, usually addresses desired performances in terms of the capability to fulfill given missions and tasks. Typically, at this design stage, not enough details are available to assess other fundamental properties of the rotorcraft. Among others, handling qualities (HQs) are quite important, since they determine how safely the aircraft can be flown, and how easily pilots can accomplish required tasks while sparing enough capacity for other ones. Assessing HQs before 
flight testing may be challenging, no matter how detailed and accurate the available models are.

In the past, HQs' deficiencies were often fixed a-posteriori, for instance by introducing modifications to the result of a design process that was initially driven by other, more immediate constraints and requirements [32]. This process can consume a lot of time and resources: modifications introduced at late stages of the design process will generally have a high impact on the redesign process. However, HQs are the net result of multiple design choices related to layout, structural (specifically inertial), aerodynamic and control (FCS architecture and design) parameters that might not even be available during the conceptual design stage. For this reason, their early evaluation and incorporation in the design process can be a rather challenging task.

It is also worth considering that since HQs can be rather sensitive to several design variables, whose values, in turn, might be highly uncertain at the conceptual design stage, a robust approach to evaluating the impact of design choices on HQs is needed.

One reason for HQs' evaluation not having been taken into account during the conceptual design stage in previous experiences is related to them being interwound to the pilot's behavior and perception [27, 31]. Understanding and quantifying the desirable dynamic response of an aircraft from the pilot's perspective culminated in the development of the ADS-33 design standard [1], which represented a crucial step towards making use of HQs' ratings from an engineering point of view [32].

On a parallel track, nowadays the advancement of virtual engineering tools and techniques, and in particular of both offline and pilot-in-the-loop flight simulation tools, offers at an unprecedented level the ability to thoroughly assess the flying qualities of a non-existing vehicle with a strong degree of robustness.

The development of multidisciplinary design tools for conceptual design of rotorcraft has been an active field of research in the last 15 years, at least. A statistical approach to helicopter sizing has been developed in the works of Technion, presented in Ref. [41], based on the analysis of openly available data from 180 operative single main rotor, standard layout helicopter models. The advantage claimed by Rand and Khromov of their approach resides in the ability to incorporate the effects of later stage design choices and fixes in the early design process, into a structured learn by experience framework. However, no explicit reference to HQs is made in their method. A cost-driven approach has been instead followed by Boer and Stevens, at NRL [4], in the development of the conceptual design tool SPEAR: important considerations about the average cost to perform a wide variety of mission task elements (MTE) are included in a general decision-making methodology apt at structuring the initial design of a novel vehicle. Again, no explicit reference is made to HQs. They are instead briefly mentioned in the comprehensive multidisciplinary design optimization package proposed by Khalid and Schrage in Ref. [15]: the authors cite control inputs at trim and root locus analysis referring to ADS-33 specifications but focus their attention on the global aspects of the optimization scheme, rather than detailing the process through which HQs' performances influence the vehicle design. A similar comprehensive tool, C.R.E.A.T.I.O.N., has been developed by ONERA and presented in Ref. [2] by Basset et al. It shares the multidisciplinary and comprehensive nature with the work of Khalid and Schrage at Georgia Tech, offering a unified tool for conceptual design and analysis. However, also in the description of the C.R.E.A.T.I.O.N. approach, no direct mention of HQs' assessment is made. Also the effort of DLR, presented in the work of Krenik and Weiland [16], is worthy of mention: also in this case, the developed tool is a comprehensive and unifying optimization software dedicated to the early design process of conventional (and not-so-conventional) layout rotorcraft, based on the genetic optimization paradigm. No specific reference to HQs is made in the latter case as well.

In this context, the scope of the present work is to extend an existing rotorcraft conceptual design tool, NDARC (NASA software for Design and Analysis of RotorCraft), developed by Wayne Johnson's team [14], to enhance the early design process taking into account the evaluation of HQs, and letting the results of this evaluation influence the design process. The proposed approach is to some extent similar to the one presented in the works of Lawrence et al. [17-19], in the form of the SIMPLI-FLYD software package: in both cases, the capabilities of NDARC are exploited to form the central piece of a design tool able to comprehend HQs' analysis. Two primary differences with respect to SIMPLI-FLYD and the current approach can be highlighted. The first is related to the structure of the stability augmentation system: an implicit model following technique is used in the cited works, whereas structured $H_{\infty}$ robust control framework has been chosen in this work, which further develops an idea initially presented in $[7,8]$. The rationale behind the present choice is related to the inherent uncertainty related to the values of relevant parameters at the conceptual design stage: since additional design constraints, introduced later in the design process, can lead to important modifications to said values, HQs' performances should be assessed in a framework that allows for a sufficient degree of robustness, whereas model-following of an intrinsically uncertain model may lead to results of questionable relevance. The second difference is related to the automated generation of a real-time piloted simulation model: the proposed tool can be used to build a fully nonlinear, generalpurpose multibody model of the sized rotorcraft, suitable 


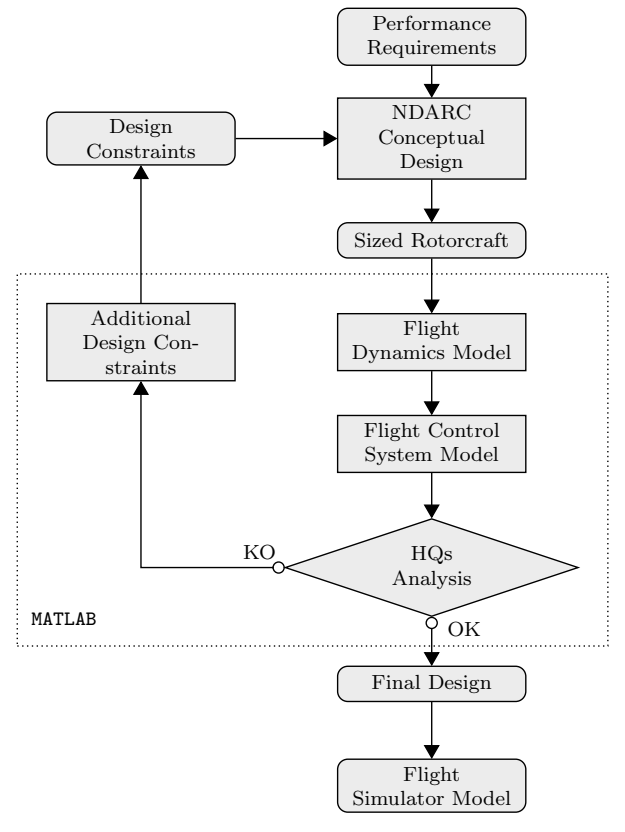

Fig. 1 Rotorcraft conceptual design tool architecture

for piloted real-time simulation, which is based on the free multibody solver MBDyn ${ }^{1}$ [20], whereas SIMPLI-FLYD can only output a linear parameter-varying model as the result of "stitching" together numerous linear time-invariant models parametrized on the flight conditions.

The following section describes the NDARC sizing of a conventional, four-bladed main rotor, twin-engine light helicopter that will serve as the reference for the discussion of the proposed method. From the NDARC output, a lowfidelity flight dynamics model is constructed as detailed in Sect. 3. The model is complemented with a stability augmentation system designed following structured $H_{\infty}$ robust control techniques: the layout and design of the FCS are dealt with in Sect. 4. The augmented system allows HQs' assessment, as described in Sect. 5. The estimation of sensitivities of HQs' performances with respect to design parameters allows the HQs' assessment to drive the redesign process. Once the design is stable, the final vehicle configuration can be used to generate the real-time multibody model for piloted simulation (Sect. 6). Finally, conclusions and future developments of the presented work can be found in Sect. 7.

Taking advantage of the lessons contained in the previous works, a toolchain is proposed, that completes and extends the rotorcraft conceptual design software NDARC, developed by NASA [12], to include HQs' assessment and robust

\footnotetext{
${ }^{1}$ www.mbdyn.org, accessed September 2021.
}

control system design. The general architecture of the toolchain is presented in Fig. 1.

The process consists of the following steps:

1. the rotorcraft initial sizing is performed using NDARC, after defining a set of performance objectives and constraints;

2. a linear flight dynamics model is set up using NDARC's output and additional design requirements;

3. a model of the flight control system is added to the flight dynamics model;

4. an evaluation of the HQs is performed on the augmented rotorcraft model using objective measures;

5. the results of the HQs' analysis are used to perform a redesign with NDARC, and the loop is repeated until the desired HQs' goals are reached.

The toolchain is developed in Matlab, and care was taken in assuring interoperability with data sources (e.g. CAD software) and towards other type of analysis. As an example, the automatic generation of a multibody model of the rotorcraft is supported. This nonlinear model is suited for real-time simulation and thus ready for use in a piloted flight simulator. The latter type of test can be extremely important in the early verification of the HQs of the rotorcraft during its sizing.

\section{Conceptual Design with NDARC}

NDARC is able to perform analysis and sizing tasks:

- the analysis task consists in an evaluation of the performances of the vehicle starting from its essential parameters, while

- the sizing task consists in using the analysis task to determine a valid set of parameters for a rotorcraft design that meets the requirements.

An NDARC optimization run receives as input the description of the rotorcraft in terms of overall architecture and desired performances or objectives (e.g. the maximization of a given performance) in specific missions and flight conditions. In the process outlined in this paper, analysis tasks are used to evaluate the sensitivity to perturbations of parameters, to externally influence the design based on the additional requirements that are posed on the HQs of the vehicle.

In the following sections, the validation and verification of the proposed tool is presented, referring to the redesign of a light helicopter that fits in the class of the Bölkow (now Airbus Helicopters) BO105 (Fig. 2a). The availability of a relevant amount of information about the $\mathrm{BO} 105$ in the 


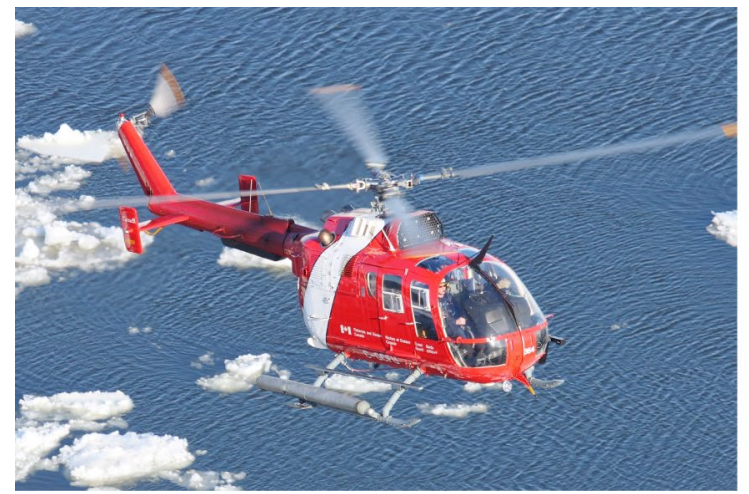

(a) The BO105 helicopter.

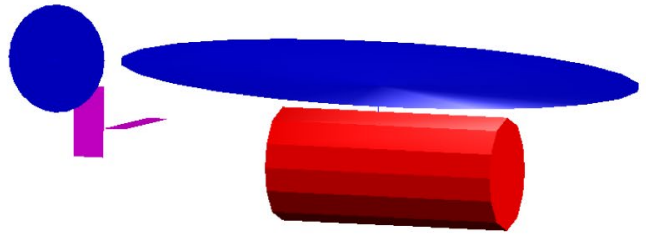

(b) Sketch of NDARC's result.

Fig. 2 The actual BO105 and the helicopter resulting from NDARC's conceptual design. The image of the BO105 is released under the Creative Commons Share-Alike Licence 3.0, by the author Simon Pierre Barrette

Table 1 BO105 sizing missions and flight conditions [24]

\begin{tabular}{lll}
\hline Requirement & Value (SI) & Value (BU) \\
\hline Max endurance & $210 \mathrm{~min}$ & $210 \mathrm{~min}$ \\
Max range & $574 \mathrm{~km}$ & $310 \mathrm{~nm}$ \\
Max speed & $268 \mathrm{~km} / \mathrm{h}$ & $145 \mathrm{kt}$ \\
Max altitude & $5180 \mathrm{~m}$ & $17,000 \mathrm{ft}$ \\
Max climb rate & $8 \mathrm{~m} / \mathrm{s}$ & $1575 \mathrm{ft} / \mathrm{min}$ \\
Max climb rate OEI & $0.5 \mathrm{~m} / \mathrm{s}$ & $984 \mathrm{ft} / \mathrm{min}$ \\
Max take-off weight & $2400 \mathrm{~kg}$ & $5290 \mathrm{lb}$ \\
Hover altitude OGE & $1584 \mathrm{~m}$ & $5200 \mathrm{ft}$ \\
Hover altitude IGE & $2286 \mathrm{~m}$ & $7500 \mathrm{ft}$ \\
Hover altitude OEI & $823 \mathrm{~m}$ & $2700 \mathrm{ft}$ \\
\hline
\end{tabular}

open literature has been a deciding factor in its selection for validation purposes (Table 1).

An initial NDARC sizing is performed, constraining the maximum available engine power and maximum take-off weight. The resulting parameters are design gross weight, empty weight and main rotor radius. Table 2 shows the results of the sizing step, compared to the actual BO105 figures. It can be noted that the sized helicopter design is very close to the $\mathrm{BO} 105$ in almost each relevant parameter.

\section{Flight Dynamics Model}

The linearized flight dynamics model (FDM) describes the dynamics of the helicopter for small perturbations about the trim conditions [28] computed by NDARC. NDARC's input parameters and those resulting from the initial sizing are directly imported in the FDM, whereas those not required nor generated by NDARC are estimated using either analytical or empirical formulas. The FDM implements a
Table 2 Results from NDARC initial sizing task

\begin{tabular}{|c|c|c|c|c|c|}
\hline Variable & BO105 & & Sized & & Diff. (\%) \\
\hline \multicolumn{6}{|l|}{ Aircraft } \\
\hline Weight empty & 1256.0 & $\mathrm{~kg}$ & 1392.9 & $\mathrm{~kg}$ & +10.9 \\
\hline $\begin{array}{l}\text { Design gross } \\
\text { weight }\end{array}$ & 2200.0 & $\mathrm{~kg}$ & 2024.7 & $\mathrm{~kg}$ & -7.9 \\
\hline Fuel tank & 400.0 & $\mathrm{~kg}$ & 342.1 & $\mathrm{~kg}$ & -14.5 \\
\hline Cruise drag & 1.11 & $\mathrm{~m}^{2}$ & 1.12 & $\mathrm{~m}^{2}$ & +0.1 \\
\hline \multicolumn{6}{|l|}{ Main rotor } \\
\hline Radius & 4.912 & $\mathrm{~m}$ & 4.671 & $\mathrm{~m}$ & -4.9 \\
\hline Disk loading & 30.37 & $\mathrm{~kg} \mathrm{~m}^{-2}$ & 29.53 & $\mathrm{~kg} \mathrm{~m}^{-2}$ & -2.8 \\
\hline $\begin{array}{l}\text { Design blade load- } \\
\text { ing }\end{array}$ & 0.0660 & & 0.0711 & & +7.7 \\
\hline Lock number & 5.09 & & 4.26 & & -16.3 \\
\hline \multicolumn{6}{|l|}{ Tail rotor } \\
\hline Disk loading & 54.49 & $\mathrm{~kg} \mathrm{~m}^{-2}$ & 56.34 & $\mathrm{~kg} \mathrm{~m}^{-2}$ & +3.4 \\
\hline $\begin{array}{l}\text { Design blade load- } \\
\text { ing }\end{array}$ & 0.0742 & & 0.0770 & & +3.8 \\
\hline
\end{tabular}

"hybrid" formulation [44], with 8 DOF for flight dynamics represented by a 10 -state linear state-space model:

- 8 states represent the 6 DOF rigid body dynamics;

- 2 states describe a first order approximation of the main rotor flapping equations.

This relatively simple formulation has been selected because despite its reduced complexity it is able to describe the fuselage-rotor couplings that $6 \mathrm{DOF}$ models cannot capture. In fact, it is known from the literature that modeling rotor dynamics may have a relevant effect on the design of control laws procedure $[9,11,43]$.

The model can be formulated in state-space form, 


$$
\dot{\mathbf{x}}=\mathbf{A x}+\mathbf{B u}
$$

with respect to the state and input vectors

$\mathbf{x}=\left\{\begin{array}{c}u \\ v \\ w \\ p \\ q \\ r \\ \phi \\ \theta \\ \beta_{1 c} \\ \beta_{1 s}\end{array}\right\} \quad \mathbf{u}=\left\{\begin{array}{c}\theta_{1 s} \\ \theta_{1 c} \\ \theta_{0} \\ \theta_{0 T}\end{array}\right\}$

The state-space matrix $\mathbf{A}$ has the following expression:
The input matrix $\mathbf{B}$ has the following expression:

$$
\mathbf{B}=\left[\begin{array}{cccc}
0 & 0 & X_{/ \theta_{0}}^{\prime} & 0 \\
0 & 0 & Y_{/ \theta_{0}}^{\prime} & Y_{/ \theta_{0 T}}^{\prime} \\
Z_{/ \theta_{1 s}}^{\prime} & 0 & Z_{/ \theta_{0}}^{\prime} & 0 \\
0 & 0 & L_{/ \theta_{0}}^{\prime} & L_{/ \theta_{0 T}}^{\prime} \\
0 & 0 & M_{/ \theta_{0}}^{\prime} & 0 \\
0 & 0 & N_{\theta_{0}}^{\prime} & N_{/ \theta_{0 T}}^{\prime} \\
0 & 0 & 0 & 0 \\
0 & 0 & 0 & 0 \\
L_{f / \theta_{1 s}}^{\prime} & L_{f / \theta_{1 c}}^{\prime} & 0 & 0 \\
M_{f / \theta_{1 s}}^{\prime} & M_{f / \theta_{1 c}}^{\prime} & 0 & 0
\end{array}\right],
$$

where, again, primed quantities are referred to the corresponding inertial (Eqs. (4) and (5)) or normalization (Eq. (6)) coefficient.

$$
\mathbf{A}=\left[\begin{array}{cccccccccc}
X_{/ u}^{\prime} & X_{/ v}^{\prime} & X_{/ w}^{\prime} & 0 & -W_{e} & X_{/ r}^{\prime}+V_{e} & 0 & -g \mathrm{c}\left(\Theta_{e}\right) & X_{/ \beta_{1 c}}^{\prime} & 0 \\
Y_{/ u}^{\prime} & Y_{/ v}^{\prime} & Y_{/ w}^{\prime} & Y_{/ p}^{\prime}-W_{e} & 0 & Y_{/ r}^{\prime}+U_{e} & g \mathrm{c}\left(\Phi_{e}\right) \mathrm{c}\left(\Theta_{e}\right) & -g \mathrm{~s}\left(\Phi_{e}\right) \mathrm{s}\left(\Theta_{e}\right) & 0 & Y_{/ \beta_{1 s}}^{\prime} \\
Z_{/ u}^{\prime} & 0 & Z_{/ w}^{\prime} & -V_{e} & Z_{/ q}^{\prime}+U_{e} & Z_{/ r}^{\prime} & -g \mathrm{~s}\left(\Phi_{e}\right) \mathrm{c}\left(\Theta_{e}\right) & -g \mathrm{c}\left(\Phi_{e}\right) \mathrm{s}\left(\Theta_{e}\right) & 0 & 0 \\
L_{/ u}^{\prime} & L_{/ v}^{\prime} & L_{/ w}^{\prime} & L_{/ p}^{\prime} & L_{/ q}^{\prime} & L_{/ r}^{\prime} & 0 & 0 & 0 & L_{/ \beta_{1 s}}^{\prime} \\
M_{/ u}^{\prime} & M_{/ v}^{\prime} & M_{/ w}^{\prime} & 0 & M_{/ q}^{\prime} & M_{/ r}^{\prime} & 0 & 0 & M_{/ \beta_{1 c}}^{\prime} & 0 \\
N_{/ u}^{\prime} & N_{/ v}^{\prime} & N_{/ w}^{\prime} & N_{/ p}^{\prime} & N_{/ q}^{\prime} & N_{/ r}^{\prime} & 0 & 0 & 0 & N_{/ \beta_{1 s}}^{\prime} \\
0 & 0 & 0 & 1 & \mathrm{~s}\left(\Phi_{e}\right) \mathrm{t}\left(\Theta_{e}\right) & \mathrm{c}\left(\Phi_{e}\right) \mathrm{t}\left(\Theta_{e}\right) & 0 & 0 & 0 & 0 \\
0 & 0 & 0 & 0 & \mathrm{c}\left(\Theta_{e}\right) & -\mathrm{s}\left(\Theta_{e}\right) & 0 & 0 & 0 & 0 \\
0 & 0 & 0 & 0 & -1 & 0 & 0 & 0 & L_{f / \beta_{1 c}}^{\prime} & L_{f / \beta_{1 s}}^{\prime} \\
0 & 0 & 0 & -1 & 0 & 0 & 0 & 0 & M_{f / \beta_{1 c}}^{\prime} & M_{f / \beta_{1 s}}^{\prime}
\end{array}\right]
$$

with $\mathrm{c}(\cdot)=\cos (\cdot), \mathrm{s}(\cdot)=\sin (\cdot), \mathrm{t}(\cdot)=\tan (\cdot)$, and primed derivatives referring to quantities normalized with respect to mass or moment of inertia, i.e.

$X_{/ j}^{\prime}=\frac{1}{m} X_{/ j} \quad Y_{/ j}^{\prime}=\frac{1}{m} Y_{/ j} \quad Z_{/ j}^{\prime}=\frac{1}{m} Z_{/ j} \quad M_{/ j}^{\prime}=\frac{1}{I_{y y}} M_{/ j}$.

Due to the inertial coupling between the roll and yaw axis, the $L_{/ j}^{\prime}$ and $N_{/ j}^{\prime}$ coefficients take the following form

$L_{/ j}^{\prime}=\frac{L_{/ j}+\left(I_{x z} / I_{x x}\right) N_{/ j}}{1-I_{x z}^{2} /\left(I_{x x} I_{z z}\right)}$

$N_{/ j}^{\prime}=\frac{N_{/ j}+\left(I_{x z} / I_{z z}\right) L_{/ j}}{1-I_{x z}^{2} /\left(I_{x x} I_{z z}\right)}$

whereas the flapping moments are normalized with respect to the flapping time constant, $\tau_{f}$, namely

$$
\begin{aligned}
L_{f / j}^{\prime} & =\frac{L_{f / j}}{\tau_{f}} \\
M_{f / j}^{\prime} & =\frac{M_{f / j}}{\tau_{f}}
\end{aligned}
$$

Stability and control derivatives are obtained from closedform analytical expressions taking into account contributions from main rotor, tail rotor, horizontal and vertical tail surfaces, and fuselage simplified aerodynamics [39]. Main rotor blades are considered rigid with twist linearly varying along the span. Empirical corrections related to tip loss and root cutout are taken into consideration. The induced velocity is uniform over the disk; tip vortex, stall and compressibility effects are neglected.

NDARC solves the trim problem that arises from force and moment equilibrium in each flight condition of interest, to find the related control inputs and aircraft attitude. Therefore, trim conditions are be imported directly in the Matlab toolchain. Small deviations from the values calculated by NDARC, arising from the difference in the reference model used to describe the rotorcraft dynamics, are usually accepted in order to avoid the additional computational cost or re-computing them.

An aspect which is worth a specific mention is the estimation of the overall moments of inertia. Since NDARC does not provide information about the actual mass distribution of the sized vehicle [13], moments of inertia have to be guessed during the preliminary computations for stability and control derivatives. Two strategies have been evaluated: 


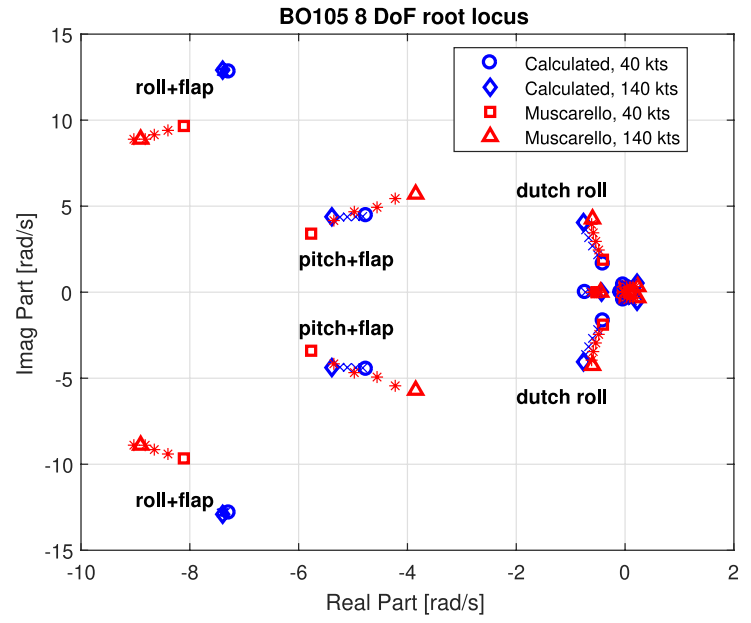

(a) Root locus

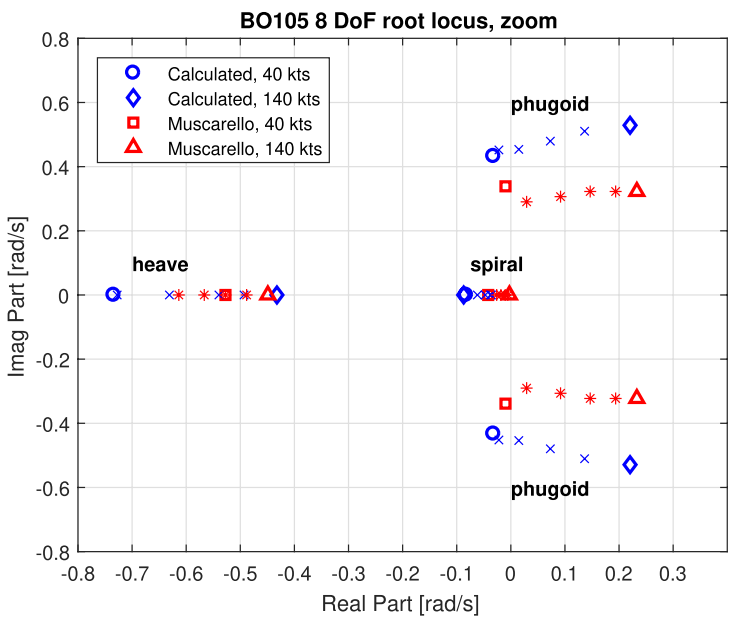

(b) Root locus zoom

Fig. 3 Root locus: BO105 8 DOF model vs. aeroservoelastic model in [26]

1. considering a uniform mass distribution and approximating the geometry and the location of the main components of the rotorcraft to that of very simple geometrical shapes;

2. guessing the values of radii of gyration of the rotorcraft main components, starting from normalized values referred to existing aircraft.

Although of limited accuracy, the first approach is more suitable for the conceptual design of a vehicle that deviates significantly from conventional ones, since it does not require any reference to a priori knowledge about the aircraft geometry. The second approach can lead to more realistic results in cases, such as the that is taken as reference in this work, in which the sized helicopter is presumably similar to an existing design. The foreseen future implementation of external software for CAD or tools for geometry generation will ease the prediction of inertial parameters.

\subsection{Flight Dynamics Model Validation}

The validation of the flight dynamics model has been obtained by comparing the root loci of the helicopter resulting from the present sizing procedure and published data referring to the BO105 helicopter operated by DLR, S123. An example of root locus resulting from the validation process is shown in Fig. 3. The poles of the present model, both in magnitude and phase, and in terms of trend with the variation of the advance ratio, $\mu$, are generally captured, in comparison with those obtained in [26] using the much more sophisticated comprehensive rotorcraft aeromechanics tool MASST [21, 22]. Considering the somewhat intrinsically low fidelity level of the data obtainable from the sizing process, and the simplifications of the present work, and taking into account that the reference eigenvalues in Ref. [26] have been obtained from a considerably more sophisticated aeroelastic model, the results are deemed satisfactory.

\section{Control System Model}

Many rotorcraft designs are intrinsically unstable, especially in the low-speed regions of the flight envelope, and their response may show significant inter-axis cross-couplings [29]. Therefore, the flight dynamics model is augmented with a flight control system model for predicting the necessary stability augmentation system's response. Moreover, whereas in the flight dynamics model inputs are fed by directly prescribing the swashplate kinematics, in the augmented one the dynamics of the actuators and the regulator are taken into account.

Modern control systems are usually implemented with digital computers, resulting in time delays caused by signal transport, processing, and filtering. For simplicity, all these delays are taken into account by coalescing them in an equivalent pure time delay. The dynamics of actuators and sensors are taken into consideration by, respectively, cascading them upstream the inputs and downstream the outputs of the bare airframe model (Fig. 4a).

To cope with low order models for the regulator synthesis and for a better physical insight into the aircraft attitude response, the augmented model is simplified. Thanks to a modal decomposition process [35], the bare airframe model is split into two 2nd-order single-axis decoupled models, respectively, representative of rotorcraft longitudinal and lateral dynamics in the frequency range 1-10 rad/s. Subsequently, an equivalent pure time delay is introduced in the reduced models to match the phase delay of the augmented 

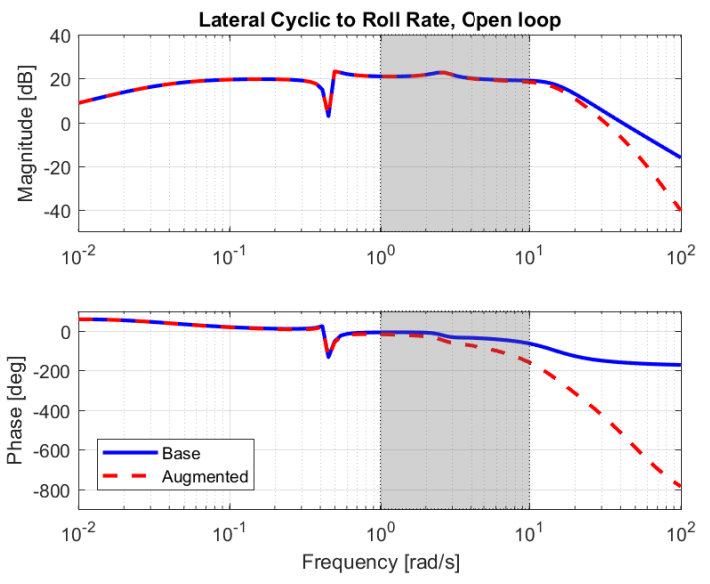

(a) Augmented model

Fig. 4 Bode plot of roll axis flight dynamics models

model (for example, Fig. $4 \mathrm{~b}$ shows the Bode plot of the roll axis dynamics).

When dealing with the conceptual design stage, the level of uncertainty of the model is too high to allow the effective design of actual control laws. At this stage, what the control laws should provide to the rotorcraft are essentially stabilization and a basic level of augmentation, to allow the assessment of its HQs. The structure of the control laws should be simple (for example limited to static feedback gains and PID controllers), to cope with the limited fidelity level that can be expected at such an early design stage, without forgetting the feasibility of their practical implementation.

One must consider that the description of the model is intrinsically uncertain since it refers to a not-yet-existing aircraft. As such, the control design needs to be robust towards the presence of unmodeled dynamics, as well as of the possible wide variation of the model parameters. Furthermore, many requirements must be taken into account in terms of design standards and rotorcraft response capabilities during the synthesis of the regulator. In the spirit of conceptual design, the sizing of the control law should give a preliminary estimation of the amount of control effort that might be required by the final design, rather than the actual sizing of a full-featured control strategy.

Given the above-mentioned considerations, the design of the control laws implemented in the FCS model is based on the structured $H_{\infty}$ framework [42], since it represents a control synthesis technique, suitable for MIMO systems, able to cope with the inherent uncertainty of the underlying models of the plant dynamics. The structured $H_{\infty}$ methods allow the a priori definition of the structure of the control law architecture, allowing in turn to obtain low order regulators instead of fully coupled transfer matrices. Requirements for control
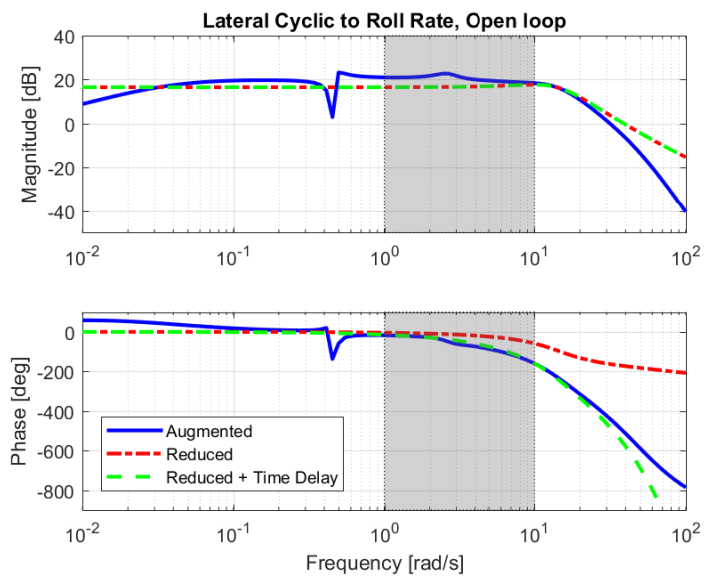

(b) Reduced model

laws are translated into frequency-dependent weight functions for performance, control action moderation, robustness, and safety. Additional weight functions are imposed on the closed-loop sensitivity functions.

A systematic approach for the application of the structured $H_{\infty}$ framework to the design of control laws for rotorcraft in multiple configurations was presented in Ref. [33]. The analysis considered:

- performance requirements;

- control action moderation requirements;

- requirements on robustness to parameter uncertainty.

\subsection{Performance}

The first aspect is addressed by an appropriate weighting of the sensitivity function, related to either command tracking or disturbance rejection performance. In the former case, the sensitivity function can be interpreted as the closedloop transfer function that connects the reference input of the pilot to the tracking error. In the latter, it represents the transfer function from an output disturbance to the output signal itself. At low frequencies, the sensitivity function has a small magnitude owing to the large gain of the loop transfer function, which means that the tracking error is kept small or that the disturbances are rejected (see Fig. 5a). Disturbance rejection bandwidth (DRB) and peak (DRP) have been proposed in Ref. [3] as suitable metrics for performance assessment in relation to disturbance rejection, along with the corresponding boundaries. The encoding of these requirements in the form of a weighting function on sensitivity is relatively straightforward. 


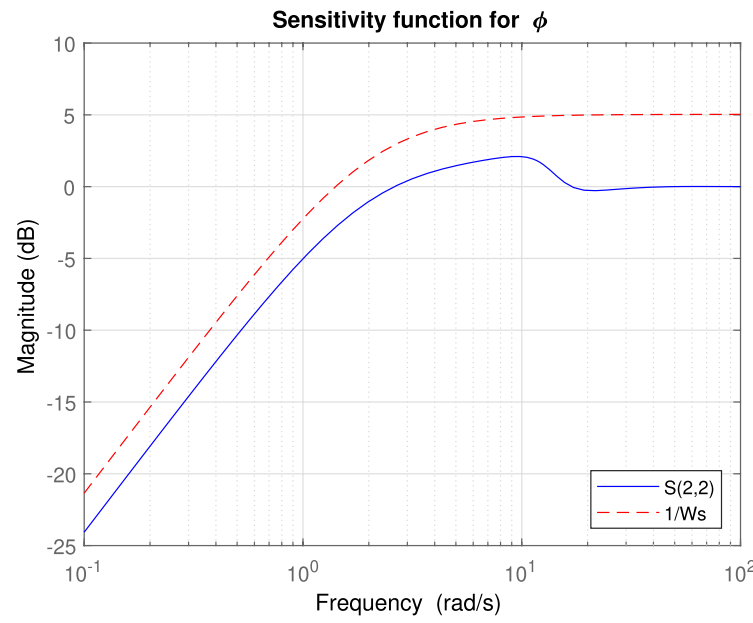

(a) Command tracking sensitivity function

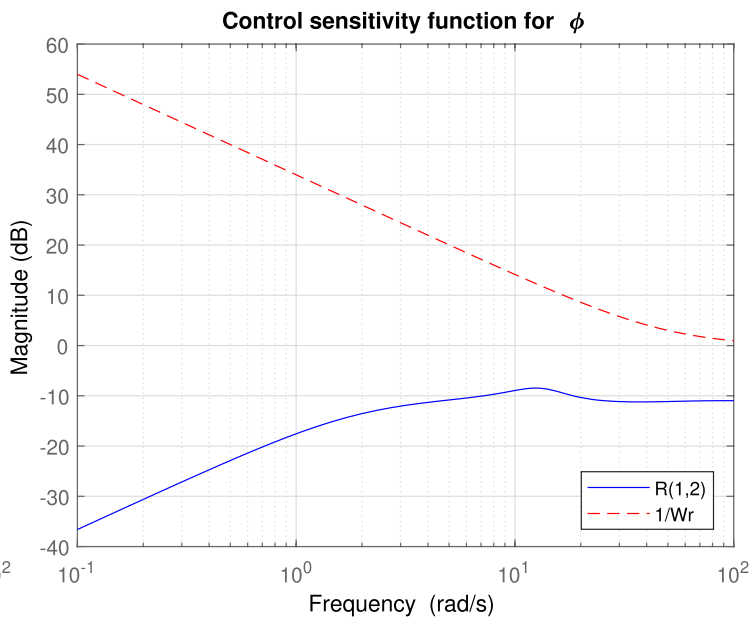

(b) Control action moderation sensitivity function

Fig. 5 Sensitivity and control sensitivity functions from regulator synthesis

\subsection{Control Action Moderation}

The control action is mediated by the actuation system: therefore, the limited bandwidth and authority of actuators has to be taken into account. Requirements on control action moderation are thus implemented by proper weighting of the control sensitivity function, i.e. the transfer function from the reference control signal to the actual control action. The transfer function represents the relationship in the frequency domain between the disturbance on the output to the control action, or equivalently between the output measurement noise and the control action itself. It is desirable to keep in all these cases the magnitude of the control sensitivity frequency response as small as possible in the frequency range beyond the system bandwidth (Fig. 5b).

\subsection{Robustness to Parameter Uncertainty}

Furthermore, a representation in the frequency domain of the model uncertainty is exploited to set the weighting of the complementary sensitivity function. In particular, the weighting function magnitude is associated with the amount of relative uncertainty between the perturbed and the nominal model, as a function of the frequency.

Robustness towards the uncertainty associated with model parameters (e.g. inertia parameters, flexbeam structural parameters, etc.) is of particular importance to guarantee the stability of the closed-loop system during the optimization process [34]. As an example, the FCS system has to exhibit a strong degree of robustness towards the values of

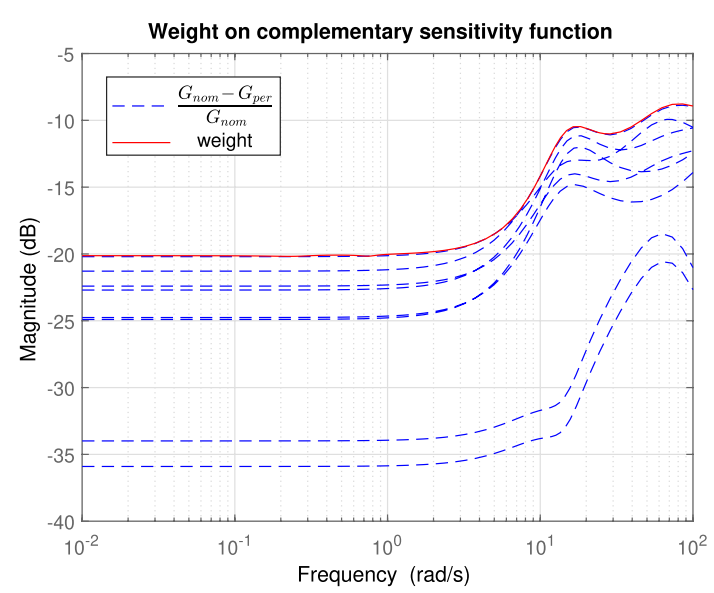

Fig. 6 Weights on sensitivity functions for regulator synthesis

airframe moments of inertia. Indeed, the latter are roughly estimated, at the current stage, as explained in the previous section. An example of weighting function choice for robustness requirements in case of uncertainty on the value of the moments of inertia is shown in Fig. 6.

A nominal model (i.e., one obtained considering nominal values for the inertia moments about the pitch and roll axes) is, therefore, considered together with a set of perturbed models, resulting from considering up to a $\pm 10 \%$ uncertainty on the moments of inertia about the roll and pitch axes.

It is to be noted that the overall flight dynamics model obtainable from the design process at the conceptual design stage is to be considered highly affected by uncertainty, with 


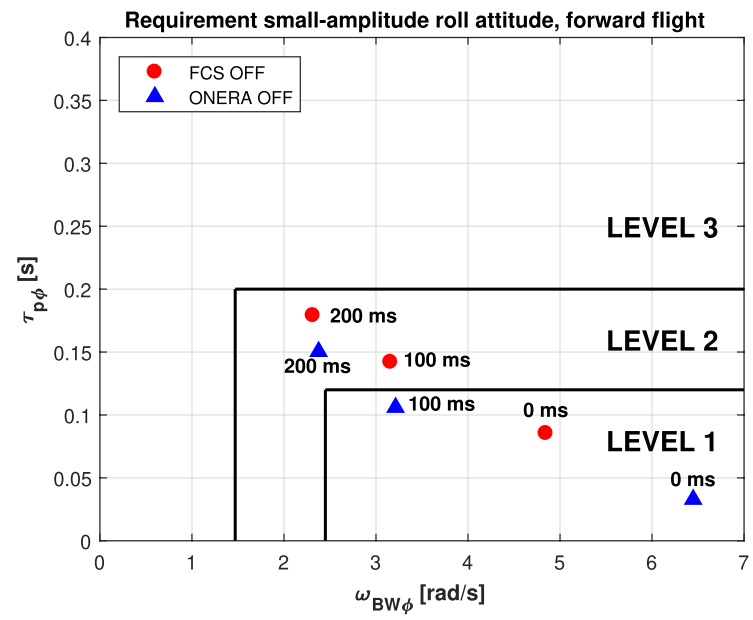

(a) FCS deactivated

Fig. 7 Comparison of bandwidth and phase-delay with data from [36]

no possibility to compare the behavior of the simulated aircraft to the actual one, since this stage precedes the realization of the first prototype. The choice to focus on a specific set of parameters and to not extend the analysis to others ${ }^{2}$ is to be viewed in the context of presenting a generic methodology that can be easily extended to other parameters, or to the complete model itself if deemed necessary.

The frequency weighting function associated with the variation of the rotorcraft moments of inertia is obtained considering the upper bounds of the relative error between the frequency response of the nominal and the perturbed models, at the frequencies of interest.

The relative error between the model resulting from the $i$ th perturbation and the nominal one is

$e_{i}(\omega)=\frac{G_{\mathrm{per}}^{i}(j \omega)-G_{\text {nom }}(j \omega)}{G_{\text {nom }}(j \omega)}$

where $G_{\text {nom }}(s)$ is the transfer function of the nominal model and $G_{\mathrm{per}}^{i}(s)$ is that of the model resulting from the $i$ th perturbation in the set. The upper bound is obtained as

$l(\omega)=\max _{i}\left|e_{i}(\omega)\right|$

A rational, proper transfer function is fitted to the computed values of the error upper bounds to obtain the transfer function of the uncertainty.

\footnotetext{
${ }^{2}$ Most notably, the stability derivatives, which are known to be affected by a high degree of uncertainty even when comparison with actual flight test data is possible.
}

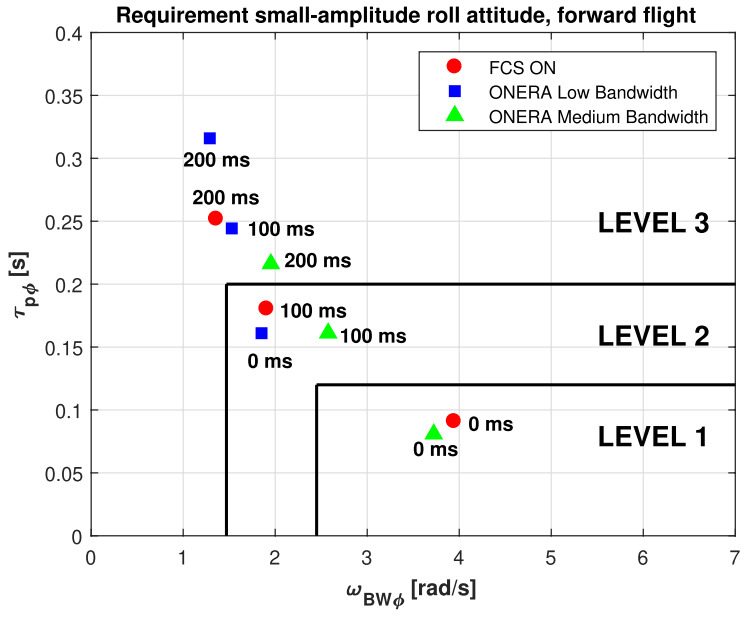

(b) FCS activated

\section{Handling Qualities Assessment}

Once the FCS model has been established, objective HQs' assessment is needed. It can be performed, for example, by evaluating the performance of the augmented model with respect to ADS-33-PRF [1] standard Bandwidth and PhaseDelay requirements. ADS-33 supports HQs' investigation through a mission-oriented approach based on mission task elements performed with different usable visual cue environments.

According to ADS-33, Bandwidth is defined as the lesser of two frequencies, the phase-limited and gain-limited bandwidth, $\omega_{\mathrm{BW}}$, derived from the phase and gain of the frequency response of roll attitude to pilot's cyclic control, expressed in radian per second and, respectively, indicated as $\omega_{\mathrm{BW}_{\phi}}$ and $\omega_{\mathrm{BW}_{\text {gain }}}$, the former usually being the lesser. Phase-delay is defined as

$\tau_{p}=\frac{\Delta \Phi_{2 \omega_{180}}}{57.3\left(2 \omega_{180}\right)}$,

in seconds, where $\Delta \boldsymbol{\Phi}_{2 \omega_{180}}$ is the difference, expressed in degrees, between the phase response at twice the frequency whose phase is $-180^{\circ}, \omega_{180}$, and $-180^{\circ}$ itself. By placing the resulting Bandwidth and Phase-Delay values in a chart that resembles that of Fig. 7 one can determine the expected HQ level for that specific MTE.

Since the aircraft model describes the linearized dynamics of the vehicle for small perturbations about a trim condition, the handling qualities assessment has to be tailored to mission task elements that would involve large amplitude responses. For this reason, at the current stage, a frequency domain analysis of the roll response to small-amplitude lateral cyclic inputs is employed, analyzing the ability of 


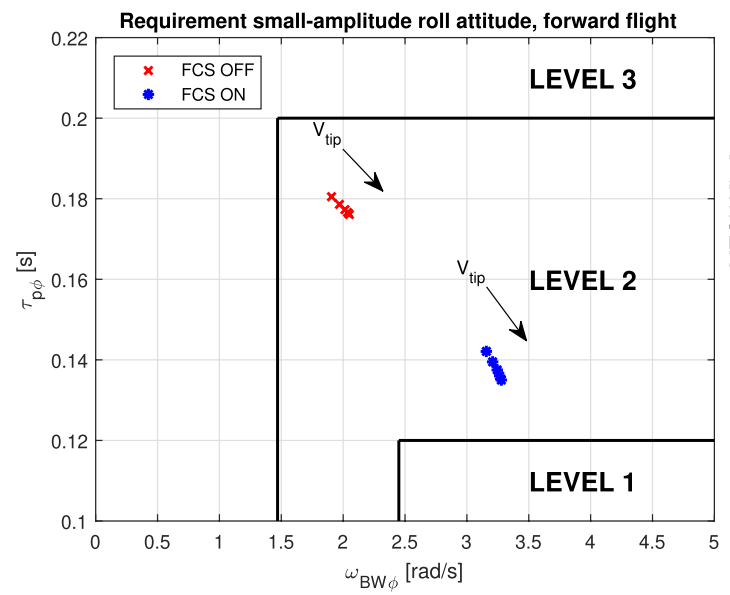

(a) Bandwidth and Phase-Delay method

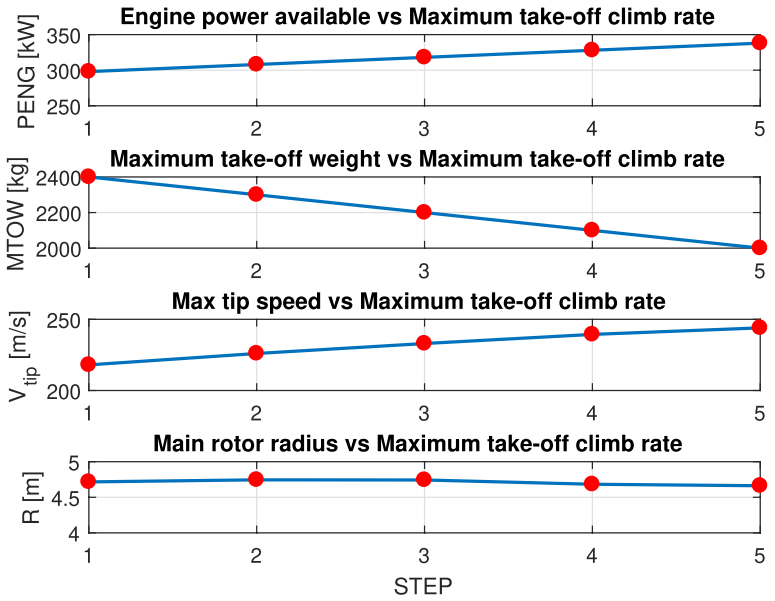

(b) Main parameters variation

Fig. 8 Example of results with closure of the loop

the rotorcraft to perform closed-loop compensatory tracking. The lateral response is also very important in the prediction of the aircraft proneness to Aircraft/rotorcraft pilot couplings (A/RPC) phenomena, and in particular of Pilot Induced Oscillations (PIO) [37], originating from unwanted interaction between the pilots' and the rotorcraft's dynamics. RPCs can potentially result in instabilities which can degrade flying qualities and can even result in catastrophic loss of control events.

In Fig. 7, the predicted response of the aircraft is validated against results presented in the literature for the BO105. When the simplified FCS based on the proposed robust approach is activated, the differences in HQs' ratings between the BO105 and the helicopter model resulting from the sizing process reduce significantly. The Figure reports the Bandwidth and Phase-Delay parameters with reference to the limits defined in ADS-33 for "Target Acquisition and Tracking" defined in Section 3.4.6 "Roll attitude response to lateral controller" for "Small-amplitude roll attitude response to control inputs (bandwidth)" (3.4.6.1).

Results from HQs' assessment are used to modify NDARC input parameters and a redesign process starts with the aim of improving HQs' levels and ratings. The methodology implemented in the proposed tool is inspired by previous work in this sense by Yilmaz et al. [45]. The input parameters in subsequent NDARC optimization runs are varied to move points in the Bandwidth/Phase-Delay plane towards higher HQs' ratings. Figure 8a shows some example results of such process, applied to main rotor tip speed: as this parameter increases, HQs' ratings generally increase. Increasing the main rotor tip speed, however, requires the relaxation of other design constraints: e.g., an increase of the maximum available engine power or a reduction of the maximum take-off weight.
When these input parameters are modified in the NDARC sizing task, the other sized quantities are also affected, in some cases with different trends. This is the case, for example, of the main rotor radius. Indeed, when tip speed and engine power available are increased the radius decreases, whereas it increases when the tip speed is increased and the maximum take-off weight is decreased.

The implemented redesign logic leverages the capability to determine those parametric sensitivities, with the aim of keeping specific quantities as constant as possible (in the example case, the main rotor radius). Figure 8 b shows the variation of the main sizing parameters in subsequent redesign iterations and the corresponding limited variation of the main rotor radius. This process can be developed into a powerful tool for the designer, enabling the reduction of the number of variables to be monitored and the simultaneous reduction of the variation of quantities of interest.

Modifications with respect to the initial sizing, driven by HQs' assessments, have been purposely exaggerated in the present work, to highlight the effects of an HQs-driven redesign process. In some cases, the resulting vehicle performances were strongly reduced. This outcome is, of course, not acceptable from an industrial point of view; from a research standpoint, however, in this way, interesting trends that can help the design of rotorcraft at the conceptual level of fidelity can be captured.

\section{Real-Time Multibody Model for Piloted Flight Simulation}

The main parameters that describe the rotorcraft at the conceptual design level of fidelity are used to generate a general-purpose, real-time capable multibody model for 
the FRAME-Sim $[6,23,46]$ flight simulation facility currently under development at Politecnico di Milano. Although often seen as double-edged swords, offline and piloted flight simulations are important in RPC investigations [38]. The proposed toolchain, and specifically the physics-based multibody simulation capability, is a valuable tool for investigating phenomena of this type [40]. The highly parameterized model is developed in the free, general-purpose multibody software MBDyn.

In its basic configuration, suited for automatic generation from NDARC's output, it is composed of $4+N_{b}$ structural nodes (one for the airframe, one for the main rotor hub, two associated with the kinematics of the fixed and rotating parts of the swashplate, and one for each of the $N_{b}$ main rotor blades), $1+N_{b}$ rigid bodies (one associated with the airframe, accounting for its inertia minus that of the main rotor, and one for each blade, the other nodes being massless), $4+N_{b}$ kinematic constraints (one prescribes the angular velocity of the hub and three are related to the swashplate kinematics), $2 N_{b}$ deformable joint elements (one for the compliance of each flexbeam, and another for that of the pitch link) introducing internal forces and moments, for a total of 114 equations in the four-blade configuration of the present work.

The main rotor is modeled using rigid blades, each connected to the hub through a spherical joint located at the equivalent hinge offset. For each blade, a deformable hinge, reacting to the blade-hub relative orientation, models the flexbeam static behavior. The tail rotor is modeled as a thrust force along the rotor axis, whose amplitude follows the simple momentum theory presented in Ref. [30, pp. 142-146].

A complete parametric model for MBDyn is formulated in a text file using its fully parametric input language through a Python pre-processor from a schematic description of the problem. A textual database with the helicopter parameters is generated from NDARC's output, complemented with additional parameters required for flight dynamics (e.g., the hinge offset). The database is parsed by MBDyn at startup, as part of its input file, to build the parametric model right before execution. Thus, the user can manually edit the database, for fine-tuning and further parametric studies.

The model is simulated in real-time with a simulation time step $\mathrm{d} t=2 \pi /(K \Omega)$, with $K \in \mathbb{N}^{+}$in the range 100-150 mainly for numerical integration accuracy requirements, resulting in $\mathrm{d} t=1 \mathrm{~ms}-1.5 \mathrm{~ms}$. Using MBDyn's NAIVE linear solver [25], the time budget is used up to $75 \%$ at the current stage, running on an Intel i7-8850H CPU at standard specifications, in single-thread mode. The flight dynamics simulation using MBDyn is fully integrated in the FRAMESim facility; as such, exactly the same tool and model can be used for offline as well as piloted flight simulations.

Doublet inputs to longitudinal and lateral cyclic commands were used to assess both models' dynamic response

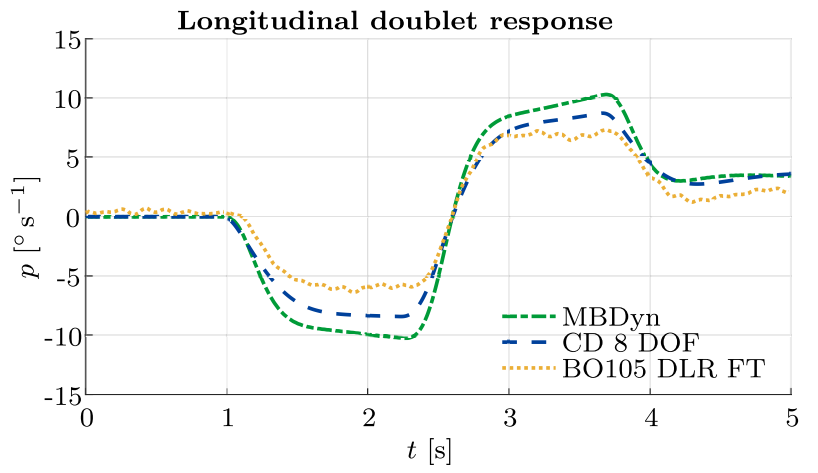

Lateral doublet response

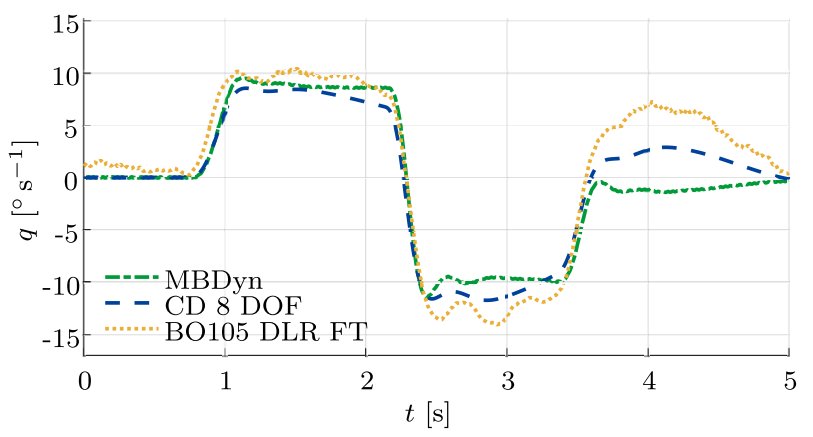

Fig. 9 On-axis responses to doublet cyclic control input of the realtime multibody model and the augmented linear 8DOF model, compared to flight test data [10]

starting from $80 \mathrm{kn}$ forward flight conditions. The type of input and the tested conditions were selected to assess the models' responses against published identification data of the DLR In-Flight Simulator BO105 ATTHes presented by Hamel and Kaletka in Ref. [10].

The aircraft is trimmed using a linear quadratic regulator (LQR) controller designed using the 8 DOF augmented linear model. The weighting of the performance indicator, in this case consisting of the entire model state, and the control input, are selected following initially the maximum allowable deviations procedure presented by Bryson and $\mathrm{Ho}$ in Ref. [5]. The initial guesses for the weights were then modified by trial and error until satisfactory results were obtained. This procedure is merely used for trimming, it is not intended to be representative of a realistic FCS.

The results of the on-axis response of the model are shown in Fig. 9, compared with the response of the 8 DOF linear model and the flight test data of the DLR BO105 ATTHes helicopter. It can be noted how the multibody model response is sufficiently representative of the designed aircraft, and how both models' responses compare favorably, especially in the roll rate response, to the flight test data. It should be highlighted that the comparison with flight test data holds significance only in qualitative terms, as the designed rotorcraft is not meant to specifically reproduce the 
BO105, but rather a rotorcraft with very similar performance characteristics.

\section{Conclusions}

After years of dedicated research, there is currently no reason for Handling Qualities not to be included in the early design process of rotorcraft. Since the assessment and quantification of the related performance has been made accessible, by the application of the ADS-33 design standard requirements and specifications to simple but sufficiently representative flight dynamics models, HQs should not only be evaluated in the conceptual design stage, but provisions should be made for them to drive the optimization processes and shape the design variables throughout the process.

This work represents an attempt to do so utilizing a hybrid, low-fidelity, state-space model of a conceptual design stage representation of a conventional helicopter layout generated by NDARC, enhanced by educated estimations to complete the aircraft description. A Flight Control System model, including the dynamics of actuators and sensors, was added to the bare airframe description: it provided an estimation of the effects of stability augmentation to the HQs' performance. To cope with the uncertain nature of the values of the relevant parameters in the initial design stage, the FCS model is sized following structured $H_{\infty}$ techniques, allowing for an adequate level of robustness.

ADS-33 Bandwidth and Phase-Delay requirements were exploited in evaluating the HQs' performances of the sized rotorcraft, to assess the current design proneness to Pilot Induced Oscillations. The ADS-33 requirements used in the HQs' evaluation were selected to further ensure robustness of the process with respect to low-fidelity nature of the flight dynamics model available at the conceptual design stage. Further development will allow for the introduction of more HQs-related requirements. The sensitivities of HQs' ratings to different layout and structural parameters of the current design were assessed, and redesign was triggered to achieve the desired balance between performance and HQs' characteristics of the sized vehicle.

Once the sizing is completed, the proposed tool is able to automatically generate a fully nonlinear, real-time capable multibody model of the aircraft, aimed at pilot-in-the-loop simulations. The model is written with the aim of coupling the conceptual design tool to the capabilities of FRAMESim, the helicopter flight simulation facility and software framework in development at Politecnico di Milano. The procedure has been developed with the further goal of preparing the tool for the generation of higher fidelity models of the sized rotorcraft aeroservoelastic behavior.

The current work focused on a conventional layout: a four-blade main rotor, twin engine light helicopter that has been sized using available data of the Bölkow BO105, for validation purposes. Future developments will focus on nonconventional configurations, including tiltrotor aircraft and other advanced air mobility concepts, in an attempt to fully exploit the capabilities of the conceptual design tool and to further generalize the methods here proposed.

Acknowledgements The authors gratefully acknowledge Dr. Wayne Johnson and NASA Ames Research Center for providing access to and guidance for the use of NDARC, professor Marco Lovera and Dr. Simone Panza, at Politecnico di Milano, for the useful discussions and the guidance in implementing the robust control augmentation, and $\mathrm{Mr}$. Matteo Daniele, also at Politecnico di Milano, for his support in the refinement of the multibody models.

Funding Not applicable.

Availability of Data and Materials Data used in this work were obtained from the open literature as described in the manuscript.

Code Availability NDARC was obtained from NASA under a NDA. MBDyn is free software, available from http:/www.mbdyn.org/. All other relevant software was internally developed as described in the manuscript; it may be obtained by direct request to the authors.

\section{Declarations}

Conflict of interest The author(s) declare no competing interests.

Open Access This article is licensed under a Creative Commons Attribution 4.0 International License, which permits use, sharing, adaptation, distribution and reproduction in any medium or format, as long as you give appropriate credit to the original author(s) and the source, provide a link to the Creative Commons licence, and indicate if changes were made. The images or other third party material in this article are included in the article's Creative Commons licence, unless indicated otherwise in a credit line to the material. If material is not included in the article's Creative Commons licence and your intended use is not permitted by statutory regulation or exceeds the permitted use, you will need to obtain permission directly from the copyright holder. To view a copy of this licence, visit http://creativecommons.org/licenses/by/4.0/.

\section{References}

1. Performance specification, handling qualities requirements for military rotorcraft. ADS 33-E-PRF, US Army AMCOM, Redstone Arsenal, Alabama, USA (2000)

2. Basset, P.M., Tremolet, A., Cuzieux, F., Schulte, C., Tristrant, D., Lefebvre, T., Reboul, G., Costes, M., Richez, F., Burguburu, S., Petot, D., Paluch, B.: The C.R.E.A.T.I.O.N. project for rotorcraft concepts evaluation: the first steps. In: 37th European Rotorcraft Forum. Gallarate, Italy (2011)

3. Berger, T., Ivler, C., Berrios, M., Tischler, M., Miller, D.: Disturbance rejection handling qualities criteria for rotorcraft. In: 72nd Annual Forum of the American Helicopter Society, West Palm Beach, USA (2016)

4. Boer, J.F., Stevens, J.: Helicopter life cycle cost reduction through pre-design optimisation. In: 32nd European Rotorcraft Forum, Maastricht, The Netherlands (2006) 
5. Bryson, A.: Applied Optimal Control: Optimization, Estimation and Control, chapter 5. CRC Press, Boca Raton (1975)

6. Quaranta, G., Daniele, M., Masarati, A.Z.: Pilot in the loop simulation of helicopter-ship operations using virtual reality. Aerotecnica Missili Spazio 99(1), 53-62 (2020). https://doi.org/10.1007/ s42496-020-00037-3

7. Gerosa, G., Zanoni, A., Panza, S., Masarati, P., Lovera, M.: A handling qualities oriented approach to rotorcraft conceptual design. In: AHS 74th Annual Forum. Phoenix, AZ, USA (2018)

8. Gerosa, G., Zanoni, A., Panza, S., Masarati, P., Lovera, M.: Augmented rotorcraft conceptual design driven by handling qualities requirements. In: EuroGNC19, 5th CEAS Conference on Guidance, Navigation and Control., Milan, Italy (2019)

9. Hall, W.E., Jr., Bryson, A.E., Jr.: Inclusion of rotor dynamics in controller design for helicopters. J. Aircr. 10(4), 200-206 (1973)

10. Hamel, P.G., Kaletka, J.: Advances in rotorcraft system identification. Progr. Aerosp. Sci. 33(3), 259-284 (1997). https://doi.org/ 10.1016/S0376-0421(96)00005-X

11. Ingle, S.J., Celi, R.: Effects of higher order dynamics on helicopter flight control law design. J. Am. Helicopter Soc. 39(3), 12-23 (1994)

12. Johnson, W.: NDARC-NASA design and analysis of rotorcrafttheoretical basis and architecture. In: American Helicopter Society Aeromechanics Specialists' Conference, San Francisco, CA, USA (2010)

13. Johnson, W.: NDARC-NASA design and analysis of rotorcraftvalidation and demonstration. In: American Helicopter Society Aeromechanics Specialists' Conference, San Francisco, CA, USA (2010)

14. Johnson, W., Branch, A.: NDARC-NASA design and analysis of rotorcraft. validation and demonstration. In: American Helicopter Society Aeromechanics Specialists' Conference (2010)

15. Khalid, A., Schrage, D.P.: Helicopter design cost minimization using multidisciplinary design optimization. In: AHS 63rd Annual Forum, Virginia Beach, VA (2007)

16. Krenik, A., Weiand, P.: Aspects on Conceptual and Preliminary Helicopter Design. Deutsche Gesellschaft für Luft-und Raumfahrt-Lilienthal-Oberth eV (2016)

17. Lawrence, B.: Incorporating handling qualities analysis into rotorcraft conceptual design. In: American Helicopter Society International-Rotorcraft Handling Qualities Specialists' Meeting 2014, Huntsville, AL, USA, pp. 83-105 (2014)

18. Lawrence, B., Field, M., Theodore, C.R., Field, M., Berger, T.: Handling qualities optimization for rotorcraft conceptual design. In: Rotorcraft Virtual Engineering Conference, Liverpool, UK (2016)

19. Lawrence, B., Theodore, C.R., Johnson, W., Berger, T.: A handling qualities analysis tool for rotorcraft conceptual designs. Aeronaut. J. 122(1252), 960-987 (2018). https://doi.org/10.1017/ aer.2018.43

20. Masarati, P., Morandini, M., Mantegazza, P.: An efficient formulation for general-purpose multibody/multiphysics analysis. J. Comput. Nonlinear Dyn. (2014). https://doi.org/10.1115/1.4025628

21. Masarati, P., Muscarello, V., Quaranta, G.: Robust aeroservoelastic stability of helicopters: application to the air/ground resonance. In: American Helicopter Society 67th Annual Forum, Virginia Beach, VA (2011)

22. Masarati, P., Muscarello, V., Quaranta, G., Locatelli, A., Mangone, D., Riviello, L., Viganò, L.: An integrated environment for helicopter aeroservoelastic analysis: the ground resonance case. In: 37th European Rotorcraft Forum, Gallarate, Italy, pp. 177.1$177.12(2011)$

23. Masarati, P., Zanoni, A., Quaranta, G.: Physics-based piloted flight simulation using multibody dynamics. In: ASME IDETC/ CIE 2016, Charlotte, NC, USA. DETC2016-60385 (2016)
24. McConkey, E.D., Anoll, R.K., Renton, M.B., Young, J.: Helicopter physical and performance data. Technical report, Systems Control Technology, Inc., Arlington, VA (1991)

25. Morandini, M., Mantegazza, P.: Using dense storage to solve small sparse linear systems. ACM Trans. Math. Softw. 33(1), 5 (2007). https://doi.org/10.1145/1206040.1206045. (1-12)

26. Muscarello, V., Quaranta, G., Masarati, P., Lu, L., Jones, M., Jump, M.: Prediction and simulator verification of roll/lateral adverse aeroservoelastic rotorcraft-pilot couplings. J. Guidance Control Dyn. 39(1), 42-60 (2015)

27. Padfield, G.D.: The making of helicopter flying qualities: a requirements perspective. Aeronaut. J. 102(1018), 409-437 (1998). https://doi.org/10.1017/S0001924000027627

28. Padfield, G.D.: Helicopter Flight Dynamics: The Theory and Application of Flying Qualities and Simulation Modelling, Chap. 4, pp. 206-238. Blackwell Publishing, Hoboken (2007)

29. Padfield, G.D.: Helicopter Flight Dynamics: The Theory and Application of Flying Qualities and Simulation Modelling, Chap. 2, pp. 63-65. Blackwell Publishing, Hoboken (2007)

30. Padfield, G.D.: Helicopter Flight Dynamics: The Theory and Application of Flying Qualities and Simulation Modelling, Chap. 3, pp. 142-146. Blackwell Publishing, Hoboken (2007)

31. Padfield, G.D.: Capturing requirements for tiltrotor handling qualities-case studies in virtual engineering. Aeronaut. J. 112(1134), 433-448 (2008). https://doi.org/10.1017/S0001924000002402

32. Padfield, G.D.: Rotorcraft handling qualities engineering: managing the tension between safety and performance. J. Am. Helicopter Soc. 58(1), 1-27 (2013). https://doi.org/10.4050/JAHS.58.011001

33. Panza, S.: Structured flight control law design for helicopters and tiltrotors. Ph.D. thesis, Politecnico di Milano, Dipartimento di Scienze e Tecnologie Aerospaziali (2018)

34. Panza, S., Lovera, M.: Rotor state feedback in helicopter flight control: robustness and fault tolerance. In: IEEE Multi-Conference on Systems and Control, Antibes-Nice, France (2014). 10.1109/ CCA.2014.6981387

35. Panza, S., Lovera, M.: Rotor state feedback in the design of rotorcraft attitude control laws. In: 3rd CEAS Specialist Conference on Guidance, Navigation and Control, Toulouse, France (2015)

36. Pavel, M.D., Götz, J., Vu, B., Jump, M.: Adverse rotorcraft-pilot coupling: Prediction and suppression of rigid body RPC: sketches from the work of GARTEUR HC AG-16. In: 34th European Rotorcraft Forum, 1-15, 2008. Royal Aeronautical Society (2008)

37. Pavel, M.D., Jump, M., Dang-Vu, B., Masarati, P., Gennaretti, M., Ionita, A., Zaichik, L., Smaili, H., Quaranta, G., Yilmaz, D., et al.: Adverse rotorcraft pilot couplings-past, present and future challenges. Prog. Aerosp. Sci. 62, 1-51 (2013)

38. Pavel, M.D., Yilmaz, D., Stroosma, O., Dang-Vu, B., Masarati, P., Quaranta, G., Gennaretti, M., Jump, M., Lu, L., Jones, M., Smaili, H., Zaichik, L.: Practices for identifying and precluding adverse aircraft- and rotorcraft-pilot couplings events-a ground simulator perspective. Prog. Aerosp. Sci. 77, 54-87 (2015). https://doi.org/ 10.1016/j.paerosci.2015.06.007

39. Prouty, R.W.: Helicopter Performance, Stability, and Control, Chap. 9, pp. 541-638. Krieger Publishing, Krieger Dr., Malabar (1995)

40. Quaranta, G., Masarati, P., Serafini, J., Gennaretti, M.: Aeroelastic rotorcraft-pilot couplings: problems and methods. Aerotecnica Missili Spazio 95(3), 176-187 (2016). https://doi.org/10.1007/ BF03404726

41. Rand, O., Khromov, V.: Helicopter sizing by statistics. J. Am. Helicopter Soc. 49(3), 300-317 (2004). https://doi.org/10.4050/ JAHS.49.300

42. Skogestad, S., Postlethwaite, I.: Multivariable Feedback Control: Analysis and Design, Chap. 9, vol. 2. Wiley, New York (2007) 
43. Tischler, M.B.: System identification requirements for highbandwidth rotorcraft flight control system design. In: American Control Conference, Boston, USA (1991)

44. Tischler, M.B., Remple, R.K.: Aircraft and Rotorcraft System Identification, Chap. 15, pp. 452-466. AIAA Education Series, Reston (2006)

45. Yilmaz, D., Pavel, M.D., Yavrucuk, I.: Helicopter design for handling qualities enhancement. In: 35th European Rotorcraft Forum, Hamburg, Germany (2009)
46. Zanoni, A., Conti, L., Masarati, P.: FRAME-Sim: a free-software, multibody-based, pilot in the loop rotorcraft flight simulator. In: ASME IDETC/CIE 2018, Quebec City, Canada. DETC201885289 (2018)

Publisher's Note Springer Nature remains neutral with regard to jurisdictional claims in published maps and institutional affiliations. 